\title{
COVID-19 and ear endoscopy in otologic practices
}

\author{
Stephane Ayache ${ }^{1} \mathbb{D} \cdot$ Walter Kutz $^{2} \cdot$ Brandon Isaacson $^{2} \cdot$ Mohamed Badr-El-Dine $^{3} \cdot$ Joao Flavio Nogueira ${ }^{4}$. \\ Daniele Marchioni ${ }^{5} \cdot$ Livio Presutti $^{6}$
}

Received: 21 July 2020 / Accepted: 18 August 2020 / Published online: 2 September 2020

(c) Springer-Verlag GmbH Germany, part of Springer Nature 2020

\begin{abstract}
Purpose Otolaryngologists have had to postpone the majority of surgical procedures in the current COVID-19 pandemic. Airborne transmission, beyond the projection of droplets from upper airways, expose healthcare workers to a risk of viral infection. Aerosol generating procedures (AGP) increase the risk of viral transmission to staff within the operating room.

Methods Surgery of middle ear and mastoid is also considered an AGP, particularly mastoidectomy performed using a high-speed drill. The authors report their experience in endoscopic ear surgery as an alternative technique to reduce AGP in otologic procedures.

Results Transcanal endoscopic ear surgery is a reliable technique used to manage many otologic conditions.

Conclusion The endoscopic approach may reduce the risk of viral transmission to operating room staff by reducing the need for mastoidectomy.
\end{abstract}

Keywords COVID-19 $\cdot$ Ear $\cdot$ Otology $\cdot$ Endoscopy $\cdot$ Microscopy

\section{Introduction}

Many countries have adopted a strategy of quarantining their population since the beginning of the COVID-19 pandemic. The objective of these measures is to flatten the curve of infections to avoid overwhelming the healthcare system. Postponing elective surgeries, in addition to the

Stephane Ayache

s.ayache@ch-cannes.fr; ayachestef@orange.fr

1 Otology and Neurotology Unit, Department of Otorhinolaryngology-Head and Neck Surgery, Hospital Centre Simone Veil, Cannes, France

2 Department of Otolaryngology-Head and Neck Surgery, UT Southwestern Medical Center, Dallas, TX, USA

3 Department of Otolaryngology, University Hospital of Alexandria, Alexandria, Egypt

4 Department of Otolaryngology-Head and Neck Surgery, Estedualda Ceara University, Sinus and Oto Centro, Fortaleza, Brazil

5 Department of Otolaryngology-Head and Neck Surgery, University Hospital of Verona, Verona, Italy

6 Department of Otolaryngology-Head and Neck Surgery, University Hospital of Modena, Modena, Italy aforementioned measures, increases medical resources to treat COVID-19 patients.

China was the first country to report a high incidence of healthcare workers infected with COVID-19 [1]. This trend was also eventually seen in other countries that experienced a surge of COVID-19 [2, 3].

A better understanding of viral transmission leads to reduced risk for healthcare workers. It has been shown adequate personal protective equipment (PPE) substantially reduces the risk of transmission in patient care settings [4].

Aerosol generating procedures (AGP) result in a higher risk of transmission. Obvious AGPs include endotracheal intubation, tracheostomy and surgery of the airway. Surgery of middle ear and mastoid is also considered an AGP and carries a similar risk to hospital personal as other more obvious AGPs. In particular, mastoidectomy may aerosolize viral particles, resulting in a high risk of transmission to operating room staff [4].

Transcanal endoscopic ear surgery (TEES) is an effective approach to address many otologic conditions and may avoid a mastoidectomy. A more widespread use of TEES during the pandemic can reduce the need for mastoidectomy and decrease exposure to the operating room staff to COVID-19 


\section{SARS-CoV-2 and infection pathway}

The viral load within the upper airway, particularly in nasal fossa and nasopharynx [5] exposes otolaryngologists to a risk of viral infection with instrumentation of these areas. The main infection pathway of respiratory viruses involves the upper airways [6] and eyes [7]. Personal protective equipment (PPE) for healthcare workers include N95/FFP2 masks, gloves, goggles or full-face shields and gowns [4]. PPE is the best protection against the viral spread in the operating room; however, avoiding an AGP would decrease the chance of infecting operating room staff further.

\section{SARS-CoV-2 and middle ear/mastoid}

Currently, there is no evidence SARS-CoV-2 is present in the middle ear and mastoid. The presence of other respiratory viruses, including other human coronaviruses, has been identified in middle ear effusions [8]. Considering the epithelium of the middle ear and the mastoid is similar to the mucosa of the upper respiratory tract, the middle ear and mastoid may be a significant reservoir for viral particles in COVID-19 positive patients [9].

\section{Aerosolizing otologic procedures}

There is evidence airborne transmission of respiratory viruses can occur if the virus is aerosolized [10]. Mastoidectomy and other procedures that use a high-speed drill are AGPs. If the virus is present within these aerosols, the risk of a transmission of SARS-CoV-2 to the operating room staff may be significant.

\section{Background about TEES}

The endoscope was initially introduced in otology as an adjunct to the operating microscope. The limited straightline view of the microscope makes visualization of certain anatomical regions (e.g. facial recess, sinus tympani, epitympanum) difficult. This leads to a higher incidence of canal wall up and sometimes canal wall down mastoidectomy procedures.

The endoscope provides a panoramic, magnified and angled field of view of the middle ear [11, 12]. Endoscopes were initially used to inspect for residual cholesteatoma primarily in the epitympanum and the retrotympanum, after using a microscopic approach [13-17]. Advances in technology resulted in endoscopes with a smaller diameter and enhanced image definition that now facilitates a minimally invasive surgical technique using the external auditory canal as a pathway to the middle ear.

Acquired cholesteatomas originate from the tympanic membrane and extend to anatomical spaces of the middle ear and the mastoid according to ventilation routes [18]. Starting from the tympanic membrane, the cholesteatoma is removed systematically using transcanal endoscopic direct vision. A reduced need for soft tissue and bone removal, as compared to the microscope, is performed to improve the visualization of anatomical spaces, preserve mucosa and maintain gas exchange within the mastoid.

TEES provides improved visualization of the retrotympanum, thus often avoiding the need for a transmastoid posterior tympanotomy approach. Endoscopic visualization of the epitympanum is optimal, and may result in preserving the ossicular chain in the case of cholesteatoma of the lateral epitympanum [19]. Extension of cholesteatoma posterior to the dome of the lateral semicircular canal is considered the limit of the transcanal approach [20]. A traditional postauricular microscopic transmastoid approach may be used in combination with the endoscope in cases with mastoid extension.

In the current COVID-19 pandemic, recommendations have been made to postpone elective surgery and to avoid mastoidectomy, preventing infection of healthcare workers [4, 9, 21-22]. In regions where the pandemic is active, has begun to plateau or decline, the use of the endoscopy may be an alternative to aerosolizing procedures with mastoidectomy by limiting indications and extent of mastoid drilling and increasing the use of curettes whenever is possible. Endoscopic procedures, unlike using a microscope, allow for a heads-up approach in the clinic and operating room thus permitting the use of eye protection with goggles or a full-face shields.

\section{Conclusion}

TEES is uniquely suited to treat chronic otitis media during the COVID-19 pandemic. TEES often eliminates the need for a mastoidectomy, and thus avoiding an AGP that could infect the operating room staff. TEES also allows for the use of eye protection (goggles, face shields) that is more difficult to use with the microscope. The current patient care challenges posed by COVID-19 further illustrate the advantages of having different tools and approaches, such as TEES, to treat chronic otitis media.

Funding No disclosure of funding. 


\section{Compliance with ethical standards}

Conflict of interest No conflict of interest.

\section{References}

1. Wu Z, McGoogan JM (2020) Characteristics of an important lesson from the Coronavirus disease 2029 (Covid-19) outbreak in China. Summary of a report of 72314 cases from the Chinese Center of Disease Control and Prevention. JAMA. https://doi. org/10.1001/jama.2020.2648 [Online ahead of print]

2. Coronavirus Disease 2019 (Covid-19) (2019) Cases in the US. Centers for Disease Control and Prevention, updated June 28, 2020. https://www.cdc.gov/coronavirus/2019-ncov/cases-updat es/cases-in-us.html

3. Recensement national des cas de Covid-19 chez les professionnels en établissement de santé. Santé Publique France, mise à jour 11 juin 2020. https://www.santepubliquefrance.fr/etudes-et-enquetes/ recensement-national-des-cas-de-covid-19-chez-les-profession nels-en-etablissements-de-sante

4. Ayache S, Schmerber S (2020) Covid-19 and otologic/neurotologic practices: suggestions to improve the safety of surgery and consultations. Otol Neurol [Epub ahead of print]

5. Zou L, Ruan F, Huang M, Liang L, Huang H, Hong Z, Yu J, Kang M, Song Y, Xia J, Guo Q, Song T, He J, Yen HL, Peiris M, Wu J (2020) SARS-CoV-2 viral load in upper respiratory specimens of infected patients. N Engl J Med 382:1177-1179

6. Ng OT, Marimuthu K, Chia PY, Koh V, Chiew CJ, De Wang L, Young BE, Chan M, Vasoo S, Ling LM, Lye DC, Kam KQ, Thoon KC, Kurupatham L, Said Z, Goh E, Low C, Lim SK, Raj P, Oh O, Koh VTJ, Poh C, Mak TM, Cui L, Cook AR, Lin RTP, Leo YS, Lee VJM (2020) SARS-CoV-2 infection among travelers returning from Wuhan, China. N Engl J Med 382:1476-1478 [Epub ahead of print]

7. Xiao AT, Tong YX, Liu M (2020) Evaluation of coronavirus in tears and conjunctival secretions of patients with SARS-CoV-2 infection. J Med Virol 92:589-594 [Epub ahead of print]

8. Pitkäranta A, Virolainen A, Jero J, Arruda E, Hayden FG (1998) Detection of rhinovirus, respiratory syncytial virus, and coronavirus infections in acute otitis media by reverse transcriptase polymerase chain reaction. Pediatrics 102(2 Pt 1):291-295

9. Saadi RA, Bann DV, Patel VA, Goldenberg D, May J, Isildak H (2020) A commentary on safety precautions for otologic surgery during the COVID-19 pandemic. Otolaryngol Head Neck Surg 162(6):797-799
10. Workman AD, Welling DB, Carter BS, Curry WT, Holbrook EH, Gray ST, Scangas GA, Bleier BS (2020) Endonasal instrumentation and aerosolization risk in the era of COVID-19: simulation, literature review, and proposed mitigation strategies. Int Forum Allergy Rhinol 10(7):798-805

11. Ayache S, Beltran M, Guevara N (2019) Endoscopic classification of the external auditory canal for transcanal endoscopic ear surgery. Eur Ann Otorhinolaryngol Head Neck Dis 136:247-250

12. Ayache S, Beltran M, Guevara N (2017) Anatomy of the external auditory canal. Comparative study of microscope versus endoscope. Eur Rev ENT 138:93-98

13. Badr-el-Dine M (2002) Value of ear endoscopy in cholesteatoma surgery. Otol Neurotol 23:631-635

14. Thomassin JM, Korchia D, Doris JM (1993) Endoscopic-guided otosurgery in the prevention of residual cholesteatomas. Laryngoscope 103:939-943

15. Ayache S, Tramier B, Strunski V (2008) Otoendoscopy in cholesteatoma surgery of the middle ear: what benefits can be expected? Otol Neurotol 29(8):1085-1090

16. Yung MW (2001) The use of middle ear endoscopy: has residual cholesteatoma been eliminated? J Laryngol Otol 115:958-961

17. El-Meselaty K, Badr-El-Dine M, Mandour M, Mourad M, Darweesh R (2003) Endoscope affects decision making in cholesteatoma surgery. Otolaryngol Head Neck Surg 129:490-496

18. Tos M (1982) Modification of combined-approach tympanoplasty in attic cholesteatoma. Arch Otolaryngol 108:772-778

19. Marchioni D, Villari D, Mattioli F, Alicandri-Ciufelli M, Piccinini A, Presutti L (2013) Endoscopic management of attic cholesteatoma: a single-institution experience. Otolaryngol Clin N Am 46(2):201-209

20. Glikson E, Yousovich R, Mansour J, Wolf M, Migirov L, Shapira Y (2017) Transcanal endoscopic ear surgery for middle ear cholesteatoma. Otol Neurotol 38(5):e41-e45

21. Topsakal V, Rompaey VV, Kuhweide R et al (2020) Prioritizing otological surgery during the COVID-19 pandemic. B-ENT 16:55-58

22. BSO: Guidance for undertaking otological procedures during COVID-19 pandemic. https://www.entuk.org/guidance-undertakin g-otological-procedures-during-covid-19-pandemic. Accessed 25 Mar 2020

Publisher's Note Springer Nature remains neutral with regard to jurisdictional claims in published maps and institutional affiliations. 